\title{
The Impact of Organizational Creativity on Organization Agility: The Moderating Role of Knowledge Sharing in Pharmaceutical Companies in Jordan
}

\author{
Submitted 15/06/21, 1st revision 12/07/21, 2nd revision 27/07/21, accepted 28/08/21
}

Shaima'a Abdelqader Jaffal ${ }^{1}$, Ziad Ali Eid Alshawabkeh ${ }^{2}$

\begin{abstract}
:
Purpose: This study aims to identify the effect of organizational creativity on agility in Jordanian pharmaceutical companies and explain the moderating role of knowledge sharing. Design/Methodology/Approach: To accomplish the study's objectives, a hypothetical model is presented to reflect the impact of the study variables using a model consisting of research hypothesis divided into four sub-hypotheses. A designed questionnaire has been developed for this purpose, distributed among workers in different supervisory and administrative positions from the upper and middle management in the researched companies through a targeted sample of (350) subjects. The data are analyzed using descriptive and analytical statistical methods and the Statistical Package for Social Sciences (SPSS).

Findings: The analysis mainly shows that the entire dimensions of organizational creativity have reached high degrees of importance, according to the respondents' answers. It is also revealed that there is an impact of organizational creativity on its various dimensions in the Jordanian pharmaceutical companies.

Practical Implications: The study recommends that companies establish concerned with creativity and organizational development to adapt and develop creative ideas which might help and back organizations to be developed in the light of sharing the knowledge which improves creativity in organizations and creates organizational agility, which is positively reflected on the organization, its performance, and its development.

Originality/Value: The study depends on different dimensions by reviewing previous English and Arabic language studies using four organizational creativity dimensions, strategic view, encourage and embrace creativity, internal work environment, and organizational culture.
\end{abstract}

Keywords: Organization's agility, organizational creativity, knowledge sharing, competence, flexibility, speed, responsiveness, strategic view, encourage and embrace.

JEL Classification: $O 1, O 2$.

Research type: Research article.

\footnotetext{
${ }^{1}$ Petra University, sjaffal@uop.edu.jo;

${ }^{2}$ Assistant professor, Department of Business Administration, Faculty of Business, Al-Balqa Applied University, Jordan, z.alshwabkeh@bau.edu.jo;
} 


\section{Introduction}

Business organizations always work to achieve their goals and maintaining their renovation and development. Henceforth, this objective urges them towards development, innovation, and creativity in business, which stimulates the production and increases its flow through technology and the improvement of different systems, generating profits and competition in the market, achieving efficiency and flexibility in working to achieve the goals of the organization and its continuity.

Until recently, there has been a body of research about knowledge sharing and its importance in generating inputs and outputs in various fields concerning production sectors and service ones, taking into consideration the Jordanian pharmaceutical companies whose primary interest is evident in the creativity and innovation of unexplored areas in the pharmaceutical industry. Thus, this study examines organizational creativity's effect on agility and the moderating role of knowledge sharing in Jordanian pharmaceutical companies.

\section{Literature Review}

Examining the other research carried out in organizational creativity, the researchers conclude that the measures or variables adopted by have not been found collectively in a study. Accordingly, the researchers adopt various measurements eclectically collected from several studies to comprehensively define the nature of the relationship between the integrated variables whose investigation provides partial results in the literature. Then, the researchers attempt to crystallize the study problem by testing the effect of organizational creativity on organizational performance in the moderating role of knowledge sharing in Jordanian pharmaceutical companies. Besides, they investigate to what extent organizational creativity is found in the chosen Jordanian pharmaceutical companies, concentrating on the organization's level of agility and the change that might occur due to the moderating role of knowledge sharing. The present study seeks to answer the following questions:

1. What is the level of organizational innovation that characterizes the Jordanian pharmaceutical companies?

2. What is the level of the organization's agility depicted in the Jordanian pharmaceutical companies?

3. To what extent does the level of knowledge sharing involve in Jordanian pharmaceutical companies?

4. Does organizational innovation in Jordanian pharmaceutical companies affect the organization's agility?

5. Does knowledge sharing moderate the impact of organizational innovation on the agility of Jordanian pharmaceutical companies? 
Figure 1. The Sample of the Study

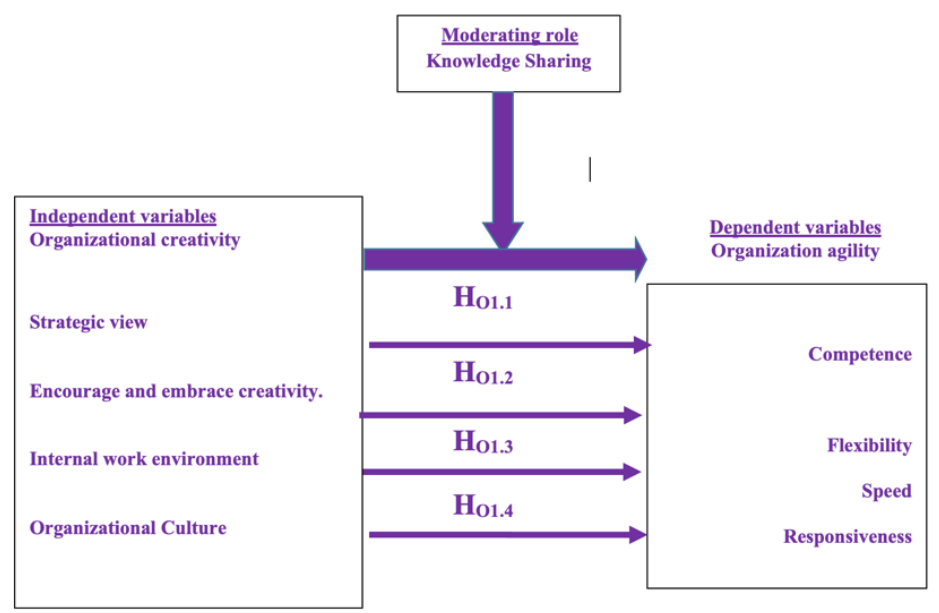

Source: Structure based on previous studies.

The reserch hypothesis $(\mathrm{HO1})$ is: There is no statistically significant impact $(\alpha \leq 0.05)$ of organizational creativity with their dimensions (strategic view, encourage and embrace creativity, internal work environment, organizational culture) on the organization agility with the existence of knowledge sharing as a moderating variable in the Jordanian pharmaceutical companies. Four sub-hypotheses emerge from it.

H01.1: There is no statistically significant impact $(\alpha \leq 0.05)$ of organizational creativity with their dimensions (strategic view, encourage and embrace creativity, internal work environment, organizational culture) on the competence with knowledge sharing as a moderating variable in the Jordanian pharmaceutical companies.

H01.2: There is no statistically significant impact $(\alpha \leq 0.05)$ of organizational creativity with their dimensions (strategic view, encourage and embrace creativity, internal work environment, organizational culture) on the flexibility with knowledge sharing as a moderating variable in Jordanian pharmaceutical companies.

H01.3: There is no statistically significant impact $(\alpha \leq 0.05)$ of organizational creativity with their dimensions (strategic view, encourage and embrace creativity, internal work environment, organizational culture) on the speed with knowledge sharing as a moderating variable in Jordanian pharmaceutical companies.

H01.4: There is no statistically significant impact $(\alpha \leq 0.05)$ of organizational creativity with their dimensions (strategic view, encourage and embrace creativity, internal work environment, organizational culture) on responsiveness with knowledge sharing as a moderating variable in Jordanian pharmaceutical companies.

Organizational Creativity: Organizational creativity is the creation of new and valuable ideas (Olszak and Kisielnicki, 2016). Organizational creativity means something that reflects the creation of value, goods, services, ideas, and processes and 
reflects the entrepreneurial capabilities of workers and employees regardless of the administrative level to deal with complex environments (Vasconcellos et al., 2018). Researchers have adopted various perspectives on organization creativity, the outcome view emphasizes novel and valuable products, processes, services, and strategies, the process view focuses on how creative outcomes are produced (Nisula and Kianto, 2018). Organizational creativity means generating new and valuable ideas concerning products, services, processes, managerial practices, and competitive strategies (Olszak et al., 2018; Norena-Chavez, 2020).

Many researchers have depended on creative organizational climate dimensions. In this study, the researcher depends on different dimensions by reviewing previous English and Arabic language studies. The researcher uses four organizational creativity dimensions, strategic view, encourage and embrace creativity, internal work environment, and organizational culture.

Strategic View: It is a future vision for the company and by developing a vision that expresses the ideal state of the company and which the company wants and aspires to reach in the future, in addition to setting and designing the message that expresses the entity of the company, the reason for its existence and its philosophy, and the strategic outlook is usually linked to the leaders or the higher management of the company as leaders realize the extent of their influence on the subordinates as they exercise their powers and charisma (personal qualities) that they possess and motivate subordinates to achievement (Al-Mobaideen, 2009).

Furthermore to innovation and creativity, as leaders and their attributes change, which requires creative work, renewal and changing what is present, and from here the importance of leadership appears through a long-term strategic view that encourages and supports innovation and seeks to advance the company and grow in the long term, and this will only be achieved through innovation, as these leaders are also distinguished by their clarity of future vision and their ability to give subordinates the freedom to act (Al Dahan et al., 2018), this in itself is considered support and encouragement for innovation, finding innovative ways and solutions to problems that arise, whether administrative or technical, innovating new products or carrying out improvement and development processes for current products and the management methods used in the company.

The strategic outlook requires the company to have a clear strategic plan to support the innovation process and to have specific and documented projects and work plans that are applicable and evaluated to achieve the company's strategic vision, and a methodology to support and finance development and commitment projects by senior management to support those efforts. The strategic perspective encouraged employees to expand beyond their expectations of the achievement and the critical change required and developed to achieve it (Al-Obaidiyen, 2009; Norena-Chavez and Guevara, 2020). 
Encourage and embrace creativity: Despite the differences between researchers of the concept of creativity, it is agreed that creativity is the ability to discover something new, to adapt available knowledge meaningfully, and solve problems in an original and new way that is not imitated, flexibly and effectively. Creativity is a constant encouragement to solve emerging problems and seek innovations (Baryniene and Dauknyte, 2015). Therefore, departments that adopt organizational innovation must encourage creativity and innovatively solve administrative and technical problems, unlike a previous example, to provide the appropriate organizational structure, take the method of decentralization at work, empower employees, make information available to all workers, in addition to providing material and moral incentives.

Internal work environment refers to the organization's environment from the inside, i.e., everything that affects the organization from within it and may be expressed in organizational content, financial content, human content, marketing content, compelling content, and the ability of the organization to meet its obligations. After analyzing its internal environment, the organization can come out with a set of its strengths and weaknesses (Alshawabkeh, 2020).

Organizational culture: It is a set of values, habits, beliefs, and expectations that the organization members share and lead to the adaptation of the new member and are passed on to future generations of workers (Dura and Jaradat, 2014). Organizational culture is one of the main determinants of organizations' success that drives all employees to organizational commitment, work, innovation, continuous improvement, participation in decision-making, achieving a competitive advantage, and rapid response to customer needs (Abdullah, 2018). Therefore, the organizational culture is essential for companies as it achieves a set of goals, the most important of which is the unity of the vision and the goal, and achieving stability in building the social company (Dura and Jaradat, 2014).

The importance of organizational creativity in organizations is apparent through the following points (Park et al., 2015: 900-901; Ramalingam et al., 2015: 194-195):

- Organizational creativity works to organize work efficiently and effectively.

- Organizational creativity is the basis of the innovation process.

- Organizational creativity works for the survival of the organization and increases competition between organizations.

- Organizational creativity works to develop and improve work procedures.

- Organizational creativity works to optimize human and material resources.

- Organizational creativity works to develop and update talent through learning, training, and practice.

- Organizational creativity works to openness by generating new ideas and facing the challenges and difficulties facing these ideas and the priorities for their implementation. 
Organizational Agility: Agility concept return in 1990, the root of agility in the manufacturing industry where adaptability to changes in the supply chain required both flexibility and nimbleness (Harraf et al., 2015). Organizational agility also involves controlling and responding to constant and rapid changes in complex environments (Darvishmotevali and Tajeddini, 2019). Organizational agility is the ability to respond to changes in their environment quickly and successfully (Bahrami et al., 2016). Organizational agility considers several fundamental capabilities that include accountability, competency, flexibility, and speed. Various definitions of agility have been proposed even now (Najme Mehdibeigi et al., 2016).

Agility is a comprehensive response to the business challenges of profitability in dynamically changing global markets characterized by high quality, performance, and personalization of the goods and services offered ( Stachowiak and Szalapka, 2018). The agility is different in concepts and domains, so after review of the literature could be recognized that it can be classified into four domains, which are introduced briefly below (Khoshlahn and Ardabili, 2016):

- Agile Manufacturing,

- Agile Software Development,

- Agile Organization/Agile Enterprise,

- Agile Workforce.

The researcher can define organizational agility as a response to an environment that changes in different variables to achieve organizational and survival goals in the market at the moment of need by using many dimensions such as responsiveness, competence, flexibility, and speed. In this study, the researcher depends on four dimensions of organizational agility responsiveness, competence, flexibility, and speed (Sharifi and Zhang Agility Model, Ghalichkhani and Hakkak, 2016).

Responsiveness refers to the ability to recognize rapid changes and reactions and using them. The response is one of the critical precedents. It expresses the company's ability to quickly adapt the changes in the external environment and market demands in transition and transformation from one product to another according to the needs and desires of customers (Al-Nashmi and Dais, 2017). It also includes developing plans to face future changes expected to occur in the external environment (Abu Abed, 2019). The response can also be achieved through accurate knowledge of customers, focusing on their perceived needs, and providing a high-quality level that is not easy for competitors to achieve (Obaid, 2017).

Competency: It represents the ability to attain organizational objectives and achievements. The skill also means efficiency and quality in performance. It refers to skill to the learned or acquired behavior, which one of its conditions is that it is directed towards achieving a specific goal or purpose and that it is organized so that it leads to the achievement of the goal in the shortest time possible. Cottrell (1999) 
defines the skill as the ability to perform and learn well whenever we want ( Al-Assaf and Muzirah, 2019).

Flexibility: It is the ability to direct different processes and attain different objectives by similar facilities. Flexibility means the ability of the company to change its operations to other ways, which requires changing both the performance of operations and the time of performing the operations, and flexibility is the critical competitive dimension in the markets as the customer's desires for change and diversity have increased, which requires companies to work on the diversity of means of satisfying these desires (Al Shawabkeh, 2016; Alshawabkeh et al., 2019).

Speed: It is the ability to carry out activities in the least possible time. Speed means reducing the time as much as possible to achieve the benefits that benefit the customers (Bilali, 2007):

- Fast delivery time: It means reducing the period between customers requesting the product until they receive the products.

- Reduce the completion period by committing to a specific period for receiving the raw materials and inputs in the production process.

- Speed of development: Speed here refers to time-related to product innovation and development and reducing it whenever possible.

Knowledge Sharing: Knowledge sharing refers to the process by which knowledge is exchanged between two or more actors (Evers and Chappin, 2020). Knowledge sharing is defined as a regular pattern of firm-level interactions that enables the transfer, recombination, or creation of knowledge and involves transferring tacit and complex knowledge across organizational units (Rungsithonga and Meyer, 2020). Knowledge sharing refers to providing task information and know-how to help others and collaborate to solve problems, develop new ideas, or implement policies or procedures (Zhang et al., 2020).

\section{Research Methodology}

The study employs the empirical analysis of data accompanied by the descriptive one to identify the impact of and of organizational creativity on organizational agility and the moderating role of "knowledge sharing." The rationale behind using this method refers to the need for an accurate analysis of the study problem through defining its variables, components, and dimensions as well as by describing the relationships between them, which presents a comprehensive scientific description of the phenomenon or the problem in question (Anderson and Poole, 2019).

The study population has been collected from various Jordanian Pharmaceutical companies whose specialty is manufacturing medicines. These companies are Dar Al Dawa', Al-Hikma Pharmaceuticals Company, the United Pharmaceutical 
Manufacturing Company, the International Drug Company, The Jordanian Swedish Medical Products Company, and the Jordanian Company for Medicine Production.

Respondents vary from the upper and middle departments' employees, Chairs of departments, and technicians. To determine the number of managers, department Chairs, and technicians, the Human Resources Management Department provides the researcher with the list approximately (405) male and female employees. So (350) questionnaires were distributed among them, using the "Purposive Sample" method. A total of (267) questionnaires were recovered, i.e., a rate of 76\%. In addition (17) questionnaires were excluded because of the respondent's incomplete responses. Henceforth, the total number of reliable questionnaires undergone the analysis was 250 , i.e., $(71.4 \%)$ of the population, which is considered a good representative of the study community (Sekaran, and Bougie, 2016).

A questionnaire has been designed as a data analysis instrument in light of the variables used to identify the impact of organizational creativity on organizations' agility. This instrument was formulated in the form of a questionnaire consisting of (62) items divided into (24) items measuring the dimensions of organizational creativity, (26) items measuring the dimensions of the organization's agility, and (12) items measuring knowledge sharing. The study adopted Likert's Five-Point Gradual Scale, which is, strongly agree ( 5 points), agree ( 4 degrees), partially agree (3 degrees), disagree (two degrees), absolutely disagree (one degree).

By reviewing the literature related to the study theme, the questionnaire was developed to tackle the following information: The first part represents questions related to the demographic characteristics of the respondents, including gender, age, educational level, academic specialization, job title, and the length of service in pharmaceutical companies. The second part represents questions related to the independent variable under organizational creativity and its four dimensions, i.e., strategic view, creativity, internal work environment, and organizational culture. This part is designed concerning studies in the area in question. The third part represents questions related to the dependent variable, organization agility, and its dimensions showing efficiency, flexibility, speed, and response according to the related literature. The fourth part represents questions related to the moderating variable, i.e., knowledge sharing.

Face validity: The researchers showed the analysis instrument to a group of Jordanian university professors specialized in this field; therefore, in light of their comments and suggestions, they made adjustments to ensure the questionnaire's items' accuracy and effectiveness, so it becomes more comprehensive and more transparent.

Construct validity: The Pearson Correlation Coefficient was employed to test the correlation of each item's score with the related main variable's total score. This helped in determining the ability of each item on the scale to be distinctive. Also, the negative correlation coefficient, less than $(0.25)$ were considered low, so preferably were deleted (Linn and Gronlund, 2012: 136). 
The scale shows that the coefficients related to the organizational creativity items in the questionnaire ranged between $(0.637-0.836)$, the coefficients relevant to the organizational agility ranged between (0.495-0.911), and the coefficients of knowledge sharing's items ranged between $(0.565-0.761)$. This result is considered statistically significant at the level of $(\alpha=0.01)$, evident about the excellent distinction of all items being higher than (0.25).

The researchers showed the instrument's reliability by calculating the value of Cronbach's Alpha coefficient for study variables. A statistically acceptable value is equal to or higher than $70 \%$. The closer the value to $100 \%$ means the better the stability scores for the study tool (Sekaran and Bougie, 2016: 325). It was found that the Cronbach alpha coefficient for the variable of organizational creativity ranges between (0.798-0.895), the agility of the organization between (0.713-0.927), and for knowledge sharing is (0.878). As a result, the combined value of the Cronbach alpha coefficients for all questionnaire items was (0.967). Such value indicates that the study instrument is consistent and that the data obtained is suitable for measuring variables and is subject to a higher degree of reliability.

\section{Results}

It is found that $62 \%$ of the study population were males, while $38 \%$ were females. Also, it was noticed that $30.4 \%$ were under 25 years old, while $17.6 \%$ were over 45 years old. According to the educational level, $47.6 \%$ of the study respondents held a master's degree, whereas 1.6\% were Ph.D. holders. Furthermore, it was found that $44.8 \%$ were specializing in pharmacy majors, but $6.8 \%$ had other specializations. $49.2 \%$ of the respondents were heads of departments, and $10.8 \%$ were technicians. $33.2 \%$ of them had years of service ranging between $10-15$ years, while $16.8 \%$ served more than 15 years in pharmaceutical companies.

\subsection{Description of the Independent Variable/Organizational Creativity}

This part of the study is related to describing the organizational creativity variable, its dimensions, the organizational agility variable, and its dimensions. The researchers calculated moderating role and knowledge sharing to determine the availability of these variables in the Jordanian pharmaceutical companies. The arithmetic means, standard deviation, and Cronbach alpha for the respondents' responses about the dimensions of organizational creativity, organization agility, and knowledge sharing, as shown in Table 1. It is clear that the values of the average of the independent variable, organizational creativity, ranged between (3.74-3.90) after the move of organizational culture to the highest point and the encouraging creativity at the lowest level. It is noted that the general index of organizational creativity reached (3.83). Thus, it is evident that applying organizational creativity to the Jordanian pharmaceutical companies was high. 
Table 1. The arithmetic means standard deviation, and Cronbach's alpha for the respondents' responses to the dimensions of organizational creativity, organization agility, and knowledge sharing

\begin{tabular}{|l|l|l|l|}
\hline Variable & $\begin{array}{l}\text { Arithmetic } \\
\text { Mean }\end{array}$ & $\begin{array}{l}\text { Standard } \\
\text { deviation }\end{array}$ & $\begin{array}{l}\text { Cronbach } \\
\text { Alpha }\end{array}$ \\
\hline Strategic view and embrace & 3.86 & .626 & 0.851 \\
\hline $\begin{array}{l}\text { Encourage } \\
\text { creativity }\end{array}$ & 3.74 & .669 & 0.895 \\
\hline Internal work environment & 3.85 & .552 & 0.817 \\
\hline Organizational Culture & 3.90 & .598 & 0.798 \\
\hline $\begin{array}{l}\text { General Indicator of } \\
\text { Organization creativity }\end{array}$ & $\mathbf{3 . 8 3}$ & $\mathbf{. 5 4 8}$ & $\mathbf{. 9 4 7}$ \\
\hline Competence & 3.77 & .630 & 0.816 \\
\hline Flexibility & 3.90 & .478 & 0.828 \\
\hline Speed & 3.81 & .489 & 0.713 \\
\hline Responsiveness & 4.12 & .660 & 0.927 \\
\hline $\begin{array}{l}\text { General Indicator of } \\
\text { organization agility }\end{array}$ & $\mathbf{3 . 9 1}$ & $\mathbf{. 4 4 9}$ & $\mathbf{. 9 2 0}$ \\
\hline $\begin{array}{l}\text { General Indicator } \\
\text { knowledge sharing }\end{array}$ & $\mathbf{3 . 8 2}$ & $\mathbf{8 . 4 6}$ & $\mathbf{0 . 8 7 8}$ \\
\hline \multicolumn{2}{|l}{} \\
Total Indicator & $\mathbf{0 . 9 6 7}$ & \\
\hline
\end{tabular}

Source: Own creation.

The values of the total average of the dependent variable, i.e., the organization's agility, ranged between (3.77-4.12) after moving response to the highest level and efficiency to the lowest level through considering a high degree of application. Therefore, the general index of the organization's agility reached (3.91). To clarify, the organization's level of agility in the Jordanian pharmaceutical companies was among the highest levels.

The values of the total average of the moderating variable (knowledge sharing) reached (3.82) and a standard deviation equalling (0.846). Hence, it becomes clear that the level of knowledge sharing in the Jordanian pharmaceutical companies was pronounced within the high levels.

The Cronbach Alpha coefficients ranged between (71.3\% -92.7\%), and the combined value of the Cronbach Alpha coefficients for all the questionnaire items were (96.7\%). Thus, the study tool can be described as consistent and that the data obtained thereof is suitable for measuring variables to a higher degree of reliability.

Multicollinearity test: The Variance Inflation Factor and Tolerance were extracted after performing the statistical treatment. Table 2 indicates that the tolerance variance factor for the independent variables was less than 1 and greater than 0.01 . The 
coefficient of variance amplification values was less than 5, which denotes the that there is no depicted correlation between the independent variables, the values are acceptable, and they are suitable for performing regression analysis (Hair et al., 2018).

Table 2. Results of the multiple correlation strength test between independent variables

\begin{tabular}{|l|l|l|}
\hline Organizational creativity & VIP & Tolerance \\
\hline Strategic view & 30.058 & .327 \\
\hline Encourage and embrace creativity & 3.089 & .324 \\
\hline Internal work environment & 2.498 & 0.400 \\
\hline Organizational Culture & 2.960 & .338 \\
\hline
\end{tabular}

Source: Own creation.

Pearson correlation coefficients were used for testing the dimensions of the independent variable to ensure that there is no high multi-linear correlation between the independent variables as it was found that the highest correlation between the independent variables is 0.769 , i.e., between the two variables, organizational culture and creativity encouragement. On the other hand, it was seen that the values of the correlation coefficient between the other independent variables were less than that, which indicates the absence of the phenomenon of high multiple linear correlations between the independent variables as there were values less than $80 \%$. Therefore, the sample is devoid of high multiple linear correlations (Gujarati et al., 2017).

The first main hypothesis test's results: The hypothesis was tested by using the Hierarchical Regression test. Results are shown in Table 3:

Table 3. Results of Hierarchical regression analysis of the impact of of organizational creativity on the organization's agility

\begin{tabular}{|c|c|c|c|c|c|c|c|}
\hline Variables & & & Beta & $\mathrm{T}$ & $\mathrm{R}^{2}$ & $\Delta \mathrm{R}^{2}$ & $\mathrm{~F}$ \\
\hline Model 1 & $\begin{array}{l}\text { Organizational creativity } \\
\text { Organization agility }\end{array}$ & & .742 & 17.45 & 0.551 & & 304.489 \\
\hline Model 2 & $\begin{array}{l}\text { Organizational creativity } \\
\text { Organization agility } \\
\text { Organizational creativity } \\
\text { Knowledge Sharing }\end{array}$ & $*$ & .922 & 10.905 & 0.697 & 0.146 & 284.103 \\
\hline
\end{tabular}

Source: Own creation.

Concerning the first sample, the researchers studied the effect of organizational creativity on the organization's agility, so it was proved that there is a significant impact of organizational creativity on the organization's agility through the value of $F$ that equaled 304.489. Such value means that there is a substantial value at 0.05 level of significance. This result is reinforced by the value of Beta equaling 0.742 and the value of T equaling 17.45, which is observed at the level of significance $\alpha \leq 0.05$. Thus, it shows through the sample that the model that organizational creativity 
was supported $55.1 \%$ of the variance in the organization's agility based on the value of $\left(\mathrm{R}^{2}\right)$.

The second sample introduced and added the formula for interaction between organizational creativity and knowledge sharing. It was revealed that there is a significant effect of the interaction formula between organizational creativity and knowledge sharing on agility, which is seen by the value of $\mathrm{F}$ for the interaction formula equaling 284.103, the value of Beta equaling 0.992, and the value of $\mathrm{T}$ equaling 10.905. This indicates that there is a pronounced impact at the level of significance $(\alpha \leq 0.05)$, and the interpretation coefficient $\left(R^{2}\right)$ recorded an increase of $14.6 \%$. Henceforth, it might be said that the knowledge sharing variable moderated the effect of organizational creativity on organizational agility, which means that the first hypotheses have been approved. It is shown that the statistical significance $\alpha \leq 0.05$ of organizational creativity by its combined dimensions on the agility of the organization in the presence of knowledge sharing has been defined as a moderating variable in the tested Jordanian pharmaceutical companies.

The First sub-hypothesis test's results: This hypothesis was tested by using the Hierarchical Regression test. The results of the hypothesis test are shown in Table 4:

Table 4. Results of Hierarchical regression analysis of the impact of of organizational creativity on efficiency

\begin{tabular}{lllllll}
\hline Variables & Competence & Beta & $\mathrm{T}$ & $\mathrm{R}^{2}$ & $\Delta \mathrm{R}^{2}$ & $\mathrm{~F}$ \\
\hline \multirow{2}{*}{ Model 1 } & $\begin{array}{l}\text { Organizational creativity } \\
\text { Organization agility }\end{array}$ & .747 & 17.69 & .558 & & 312.950 \\
\hline \multirow{2}{*}{ Model 2 } & $\begin{array}{l}\text { Organizational creativity } \\
\text { Organization agility } \\
\text { Organizational creativity * Knowledge } \\
\text { Sharing }\end{array}$ & .221 & 2.186 & .566 & $\mathbf{. 0 0 8}$ & 161.247 \\
\hline
\end{tabular}

Source: Own creation.

The first hypothesis was tested employing the Hierarchical Regression test. In the first sample, the researchers analyzed the effect of organizational creativity on efficiency to prove the significant effect of organizational creativity on the organization's competence through the value of F 312.95 at the significance level $\alpha \leq 0.05$. This result is emphasized by the value of Beta, which is equal to 0.747 , and the value of $\mathrm{T}$, which is equal to 17.690 , which is significant at the level of significance $\alpha \leq 0.05$. Therefore, it unravels that the sample of organizational creativity has explained $55.8 \%$ the variation in the organization's competence based on the value of $\left(\mathrm{R}^{2}\right)$.

The second model introduced and added the formula for interaction between organizational creativity and knowledge sharing. It was found that there is a significant effect of the interaction formula between organizational creativity and knowledge sharing on the competence of the organization, as the value of $\mathrm{F}$ for the interaction formula was 161.247, the value of Beta equaling 0.221 , and the value of $\mathrm{T}$ 
equaling 2.186 being significant at the level of significance $\alpha \leq 0.05$. The interpretation coefficient $\left(\mathrm{R}^{2}\right)$ recorded an increase of $0.8 \%$, showing that the knowledge sharing variable has moderated organizational creativity's effect on organizational competence, approving the first sub-hypothesis. The statistically significant $\alpha \leq 0.05$ for organizational creativity on the organization's efficiency in the presence of knowledge sharing has placed a moderating variable in the Jordanian pharmaceutical companies.

The second sub-hypothesis test's results: This hypothesis was tested employing the Hierarchical Regression test, as shown in Table 5:

Table 5. Results of Hierarchical regression analysis of the impact of of organizational creativity on organization's flexibility

\begin{tabular}{|c|c|c|c|c|c|c|c|}
\hline Variables & Flexibility & & Beta & $\mathrm{T}$ & $\mathrm{R}^{2}$ & $\Delta \mathrm{R}^{2}$ & $\mathrm{~F}$ \\
\hline Model 1 & $\begin{array}{l}\text { Organizational creativity } \\
\text { Organization agility }\end{array}$ & & .680 & 14.608 & .462 & & 213.386 \\
\hline Model 2 & $\begin{array}{l}\text { Organizational creativity } \\
\text { Organization agility } \\
\text { Organizational creativity } \\
\text { Knowledge Sharing }\end{array}$ & $*$ & .608 & 5.751 & .526 & .064 & 137.024 \\
\hline
\end{tabular}

Source: Own creation.

In the first sample, the results show that there is a significant effect of organizational creativity on the organization's flexibility through the value of $F$ equaling 213.386, meaning it is significant at the level of significance $\alpha \leq 0.05$. The result is emphasized by the value of Beta, which is equal to 0.680 , and the value of $T$, which is equal to 14.608 , being significant at the level of significance $\alpha \leq 0.05$. These calculations denote that organizational creativity has explained $46.2 \%$ of the variance in flexibility based on the value of $\mathrm{R}^{2}$.

Concerning the second sample, the formula for interaction between organizational creativity and knowledge sharing was introduced and added. It was found that there is a significant effect of the interaction formula between organizational creativity and knowledge sharing on flexibility, as the value of $\mathrm{F}$ for the interaction formula was 137.024, the value of Beta 0.608 , and the value of $\mathrm{T} 5.751$, which is significance at the level of significance $\alpha \leq 0.05$, and the interpretation coefficient $\left(\mathrm{R}^{2}\right)$ recorded an increase of $6.4 \%$. Therefore, it can be said that the knowledge sharing variable has modified the effect of organizational creativity in flexibility, and this indicates acceptance of the second sub-hypothesis, where a significant effect has been proven with $a \leq 0.05$ statistic of organizational creativity in its combined dimensions on flexibility in the presence of knowledge sharing as a modified variable in Jordanian pharmaceutical companies.

The third sub-hypothesis test's results: This hypothesis was tested by using the Hierarchical Regression test. The results of the hypothesis test are shown in Table 6. 
Table 6. Results of Hierarchical regression analysis of the impact of of organizational creativity on Speed

\begin{tabular}{lllllll}
\hline Variables & Speed & Beta & $\mathrm{T}$ & $\mathrm{R}^{2}$ & $\Delta \mathrm{R}^{2}$ & $\mathrm{~F}$ \\
\hline \multirow{2}{*}{ Model 1 } & $\begin{array}{l}\text { Organizational creativity } \\
\text { Organization agility }\end{array}$ & .451 & 7.968 & .204 & & 63.492 \\
\hline Model 2 2 & $\begin{array}{l}\text { Organizational creativity } \\
\text { Organization agility } \\
\text { Organizational creativity * Knowledge } \\
\text { Sharing }\end{array}$ & 1.224 & 10.853 & .461 & $\mathbf{. 2 5 7}$ & 105.585 \\
\hline
\end{tabular}

Source: Own creation.

In the first model, the researchers studied the effect of organizational creativity on speed. The results showed a significant effect of organizational creativity in speed with an $F$ value of 63.492, which is significant at the 0.05 level of significance. This result is supported by the value of Beta, which is equal to 0.451, and the value of T which is equal to 7.968 , which is significant at the 0.05 level of significance. In addition, the organizational model innovation explained (20.4\%) of the variation in speed based on the value of $\left(\mathrm{R}^{2}\right)$.

In the second model, the formula for interaction between organizational creativity and knowledge sharing was introduced and added. It was found that there is a significant effect of the interaction formula between organizational creativity and knowledge sharing on speed, as the value of $\mathrm{F}$ for the interaction formula was 105.585, the value of Beta 1.224, and the value of $\mathrm{T} 10.853$ being significant at the $\alpha \leq 0.05$ level of significance. The interpretation coefficient $\left(\mathrm{R}^{2}\right)$ recorded an increase of $25.7 \%$. Therefore, it can be said that the knowledge sharing variable has a modifying effect upon organizational creativity and speed. This indicates the acceptance of the third subhypothesis, where a significant effect has been proven with organizational creativity combined dimensions on velocity in the presence of knowledge sharing as a modified variable in Jordanian pharmaceutical companies.

The fourth sub-hypothesis test's results: This hypothesis was tested by using the Hierarchical Regression test. The results of the hypothesis test are shown in Table 7.

Table 7. Results of Hierarchical regression analysis of the impact of of organizational creativity on the respons

\begin{tabular}{llcllll}
\hline Variables & Responsiveness & Beta & $\mathrm{T}$ & $\mathrm{R}^{2}$ & $\Delta \mathrm{R}^{2}$ & $\mathrm{~F}$ \\
\hline Model 1 & $\begin{array}{l}\text { Organizational creativity } \\
\text { Organization agility }\end{array}$ & .461 & 8.170 & .212 & & 66.752 \\
\hline Model 2 2 & $\begin{array}{l}\text { Organizational creativity } \\
\text { Organization agility } \\
\begin{array}{l}\text { Organizational creativity * Knowledge } \\
\text { Sharing }\end{array}\end{array}$ & .994 & 8.238 & .382 & .170 & 76.304 \\
\hline
\end{tabular}

Source: Own creation. 
With the first model the researchers studied the effect of organizational creativity on the response. The value of $F$ equals 66.752 being significant at the $\alpha \leq 0.05$ level of significance. This result is supported by the value of Beta, which is equal to 0.461 , and the value of $T$, which is equal 8.170 being significant at $\alpha \leq 0.05$ level of significance. The model organizational creativity also has explained $21.2 \%$ of the variation in the response based on the value of $\left(\mathrm{R}^{2}\right)$.

The second model introduced and added the formula for interaction between organizational creativity and knowledge sharing. It was found that there is a significant effect of the interaction formula between organizational creativity and knowledge sharing on the response. The value of $\mathrm{F}$ for the interaction formula was 76.304, the value of Beta 0.994, and the value of $\mathrm{T} 8.238$, which is significant at the $\alpha \leq 0.05$ level of significance. The interpretation coefficient $\left(\mathrm{R}^{2}\right)$ recorded an increase of $17 \%$. Therefore, it can be said that the knowledge sharing variable has modified the effect of organizational creativity in the response, and this indicates acceptance of the fourth sub-hypothesis, where a significant effect has been proven.

\section{Discussion}

This study investigates the impact of organizational creativity on organizational agility in the moderating role, referring to the knowledge sharing in the Jordanian pharmaceutical companies. Concerning the results of the averages' values of the independent variable, organizational creativity, ranging between 3.74-3.90 after the organizational culture obtained the highest value, and after encouraging creativity be at the lowest level, the general index of organizational creativity has reached 3.83. Therefore, it has been evident that applying organizational creativity has delivered high levels in Jordanian pharmaceutical companies.

The results also showed that the values of the dependent variable organization agility, ranging between 3.77-4.12 had been seen after response obtained the highest level with a high degree of application and after efficiency became at the least and with a high degree of application. Therefore, the general index of agility has reached 3.91. Thus, it is clear that the organization's agility in Jordanian pharmaceutical companies has been within the highest levels. It has been proved that this variable has reached an average of 3.82. Thus, it is evident that knowledge sharing in Jordanian pharmaceutical companies has been within the highest levels.

The results of the central hypothesis indicate the positive change of the moderating role of knowledge sharing. By studying the effect of organizational creativity on agility, it has been proved that there is a significant effect of organizational creativity on organizational agility through the value of $\mathrm{F} 304.489$, which is significant at the level of significance $\alpha \leq 0.05$. By approving so, the value has emphasized by the value of Beta equaling 0.742 and the value of $\mathrm{T}$ equaling to 17.45 , which are significant at $\alpha \leq 0.05$ level of significance. Then, the model of organizational creativity has explained $55.1 \%$ the variance in the organization's agility based on the value of $\left(\mathrm{R}^{2}\right)$. 
When entering and adding the formula for interaction between organizational creativity and knowledge sharing, it was found that there is a significant effect of the interaction formula between organizational creativity and knowledge sharing on the organization's agility. The value of $\mathrm{F}$ for the interaction formula was 284.103, Beta value 0.992 , and the $\mathrm{T}$ value 10.905 , which is significant at the 0.05 level of significance, and the interpretation coefficient $\left(\mathrm{R}^{2}\right)$ recorded an increase of $(14.6 \%)$.

Therefore, it can be said that the knowledge sharing variable has modified the effect of organizational creativity on the organization's agility, and this indicates acceptance of the central hypothesis. It has been proven that there is a statistically significant effect for organizational creativity in its combined dimensions on the organization's agility in the presence of knowledge sharing as a modified variable in Jordanian pharmaceutical companies.

The effect of organizational innovation on the organization's efficiency through the value of $F 312.95$ is significant at $\alpha \leq 0.05$ level of significance. This result is supported by the value of Beta and is equal to 0.747 . The value of $\mathrm{T}$ was 17.690 , which is significant at the 0.05 level of significance. It appears from the model that organizational creativity has explained $55.8 \%$ of the variation in the organization's efficiency based on the value of $\left(R^{2}\right)$.

When entering and adding the formula for interaction between organizational creativity and knowledge sharing, it was found that there is a significant effect of the interaction formula between organizational creativity and knowledge sharing on the organization's efficiency. The value of $\mathrm{F}$ for the interaction formula was 161.247 , Beta value is 0.221 , and the value of $T$ is 2.186 , which is significant at $\alpha \leq 0.05$ level of significance, and the interpretation of $\left(\mathrm{R}^{2}\right)$ recorded an increase of $0.8 \%$. Therefore, it can be said that the knowledge-sharing variable has modified the effect of organizational creativity on the organization's efficiency, and this indicates acceptance of the first sub-hypothesis. A statistically significant effect has been proven for organizational creativity in its combined dimensions on the organization's efficiency in the presence of knowledge sharing as a modified variable in Jordanian pharmaceutical companies.

Furthermore, by studying the effect of organizational creativity on the organization's flexibility, the significant effect of organizational creativity on flexibility has been approved through the value of $\mathrm{F}$ equaling 213.386 , which is a significant value at the $\alpha \leq 0.05$ level of significance. This is seen as supported value of Beta equaling 0.680 and $\mathrm{T}$ equaling 14.608, which is significant at the level of significance $\alpha \leq 0.05$. It is, then, appeared that organizational creativity has explained $46.2 \%$ of the variance in flexibility based on the value of $\left(\mathrm{R}^{2}\right)$.

With the addition of the relationship between organizational creativity and knowledge sharing, it has been found that there is a significant effect of the interaction formula between organizational creativity and knowledge sharing on flexibility as the value of 
F for the interaction formula equals 137.024, the value of Beta equals 0.608. The value of $\mathrm{T}$ equals 5.751, which is significant at the significance level $\alpha \leq 0.05$. The interpretation coefficient $\left(\mathrm{R}^{2}\right)$ has also recorded an increase of $6.4 \%$. Thus, it can be said that the knowledge sharing variable has moderated the influence of organizational creativity on flexibility, approving the second sub-hypothesis.

When studying the effect of organizational creativity on speed, it has been proved that organizational creativity has a significant effect on speed through the value of $\mathrm{F}$, 63.492, which is a significant value at $\alpha \leq 0.05$ level of significance. This means that the value is emphasized by the value of Beta equaling 0.451, and T equaling 7.968 is significant at $\alpha \leq 0.05$ level of significance. Henceforth, the model indicates that organizational creativity has explained $20.4 \%$ of the variation in velocity based on the value of $\left(\mathrm{R}^{2}\right)$.

Concerning the interaction between organizational creativity and knowledge sharing, it has been revealed that there is a significant influence of the interaction formula between organizational creativity and knowledge sharing on speed as the value of $\mathrm{F}$ for the interaction formula has reached 105.585, Beta value is 1.224 and the value of $\mathrm{T}$ is 10.853, which is significant at $\alpha \leq 0.05$ level of significance. Also, the interpretation coefficient $\left(\mathrm{R}^{2}\right)$ recorded an increase of $25.7 \%$. Therefore, it can be said that the knowledge-sharing variable has moderated the effect of organizational creativity on speed, explaining the approval of the hypothesis where it is found a statistically significant effect for organizational creativity on the speed with the presence of the aforementioned moderating role in the Jordanian pharmaceutical companies.

Through studying the impact of organizational creativity on the response, it was proved that there is a significant effect of organizational creativity in the response through the value of $F$ equaling 66.752, which is a significant value at $\alpha \leq 0.05$ level of significance. The value is then supported by the value of Beta equaling 0.461 and the value of $T$ equaling 8.170, which is significant at $\alpha \leq 0.05$ level of significance. This shows that the organizational creativity model has explained $21.2 \%$ the response variance based on $\left(\mathrm{R}^{2}\right)$ value.

By adding the formula for interaction between organizational creativity and knowledge sharing, it has been that there is a significant effect of the interaction formula between organizational creativity and knowledge sharing on the response as the value of $\mathrm{F}$ equals 76.304 , the Beta value equals 0.994 , and the $\mathrm{T}$ value equals 8.238, showing a significant effect at $\alpha \leq 0.05$ level of significance. Also, the interpretation coefficient $\left(\mathrm{R}^{2}\right)$ recorded an increase of $17 \%$. Hence, it can be said that the knowledge sharing variable has moderated the effect of organizational creativity on the response variable. 


\section{Conclusion}

To sum up, this study has examined the impact of organizational creativity on organizations' agility in the presence of the moderating role of knowledge sharing in different Jordanian pharmaceutical companies. The results have shown that this impact increases in the presence of knowledge sharing. Though this study is considered one of the studies that focus on the effect of organizational creativity on agility, it inspects different variables integrated to establish a positive correlation between them and the moderating role of knowledge sharing.

It is also hoped that more studies in the future will investigate such a scope and these variables to test the increase of measures found here. Furthermore, it is recommended that companies establish concerned with creativity and organizational development to adapt and develop creative ideas which might help and back organizations to be developed in the light of sharing the knowledge which improves creativity in organizations and creates organizational agility, which is positively reflected on the organization, its performance, and its development.

\section{References:}

Abdullah, H. 2018. The mediating role of job satisfaction in the relationship between organizational culture and employee performance efficiency (application to the Sudanese Sugar Company). Master Thesis, El-Neelain University, College of Graduate Studies, Department of Business Administration. Retrieved from: http://repository.neelain.edu.sd:8080/jspui/bitstream/123456789/11996/1.

Abu Abed, M. 2019. The Impact of Organizational Agility on Achieving Career Excellence in Jordanian Telecom Companies. Master Thesis, Amman Arab University, College of Business, Amman, Jordan. Retrieved from: http://repository.neelain.edu.sd:8080/jspui/bitstream/123456789/11996/1.

Al-Assaf, J., Muzahra, A. 2019. Life Skills. Dar Ithraa for Publishing and Distribution, Amman, Jordan.

Al-Dahan, O., Ramadan, Z., Sheikh Salem, F., Makhamra, M. 2018. Modern Management Concepts. Jordan Book Center, Amman, Jordan.

Al-Faouri, E., Al-Rfou, A. 2017. The Impact of the Failure-based Learning Behavior on Organizational Agility from the Workers' Point of View in the Jordanian Industrial Companies in King Abdullah II Industrial City - Sahab. International Review of Management and Marketing, 7(3), 266-273.

Al-Mobaideen, A. 2009. The role of strategic leadership in enhancing competitiveness, an applied study on the Jordanian monarchy. Master thesis, Al-Bayt University, Mafraq, Jordan. Retrieved from: http://repository.neelain.edu.sd:8080/jspui/bitstream/123456789/11996/1.

Al-Nashmi, M., Al-Dais, H. 2017. Administrative creativity and its relationship to achieving competitive advantage in private universities in Yemen. The Arab Journal for Quality Assurance of Higher Education, 10(29), 181-199.

Alshawabkeh, Z. 2016. The Impact of Strategic Human Resource Management to Achieve A Competitive Advantage (Applied Study). Studies, Administrative Sciences, 34, 431-451. 
Alshawabkeh, Z. 2020. The Role of Organizational DNA to Enhance Strategic Balance in Commercial Banks in Madaba. Management science letters.

Alshawabkeh, Z., Aldiabat, B.F., Al-Zubeidi, M.A., Nsour, B.H., Al-Shalabi, F.S., Al-Momani, R.Z., Banyhamdan, K., Al-Abbadi, L.H. 2019. Stability Strategy and its direct role in achieving the competitive advantage at Jordanian communication Companies. Academy of Strategic Management Journal, 18(3), 1-13.

Anderson, J., Poole, M. 2019. Assignment and Thesis Writing $4^{\text {th }}$ ed. CBS Publishers \& Distributors Pvt. Ltd.

Bahrami, M., Kiani, M., Montazeralfaraj, R., Fallah Z., Mohammad, Z. 2016. The Mediating Role of Organizational Learning in the Relationship of Organizational Intelligence and Organizational Agility. Osong Public Health and Research Perspectives. doi: 10.1016/j.phrp.2016.04.007.

Baryniene, J., Dauknyte, B. 2015. Creativity as the Main Factor for Organizations Success: Theoretical Approach. European Integration Studies, 9, 235-243.

Bilali, A. 2007. Competitive Advantage and the Model of Strategic Management. Journal of Human Sciences, 11.

Celina, M., Olszak, T., Paweł, L. 2018. A comprehensive framework of information system design to provide organizational creativity support. Information \& Management, 55, 94-108.

Durrah, A., Jradat, N. 2014. Basics of strategic management: theoretical application. Dar Wael publishing and distribution. Amman, Jordan.

Evers, G., Chappin, M.M.H. 2020. Knowledge sharing in smart grid pilot projects. Energy Policy, 143, 111577.

Field, A. 2013. Discovering Statistics Using IBM SPSS Statistics $4^{\text {th }}$ ed. SAGE Publications.

Gujarati, D., Porter, D., Sangeetha, G. 2017. Basic Econometrics $5^{\text {th }}$ ed. USA, New York: The Mc Graw- Hill.

Hair, J.F., Black, W.C., Babin, B.J., Anderson, R.E., Tatham, R.L. 2018. Multivariate Data Analysis $8^{\text {th }}$ ed. Cengage Learning EMEA.

Harraf, A., Wanasika, I., Tate, K., Talbott, K. 2015. Organizational Agility. Journal of Applied Business Research (JABR), 31(2), 675-86.

Linn, R., Gronlund, N. 2012. Measurement and Assessment in Teaching, $11^{\text {th }}$ ed. Prentice Hall.

Mahlagha, D., Levent, A., Mehmet, A. 2020. The link between environmental uncertainty, organizational agility, and organizational creativity in the hotel industry. International Journal of Hospitality Management, 87, 102499.

Maryam, K., Farzad, A. 2016. The Role of Organizational Agility and Transformational Leadership in Service Recovery Prediction. Procedia-Social and Behavioral Sciences, 230, 142-149.

Najme, M., Masoud, D., Nour, M. 2016. Customer Knowledge Management and Organization's Effectiveness: explaining the mediator role of Organizational Agility. Procedia-Social and Behavioral Sciences, 230, 94-103.

Nisula, A., Kianto, A. 2018. Stimulating organizational creativity with theatrical improvisation. Journal of Business Research, 85, 484-493.

Norena-Chavez, D., Guevara, R. 2020. Entrepreneurial Passion and Self-Efficacy as Factors Explaining Innovative Behavior: A Mediation Model. International Journal of Economics and Business Administration, 8(3), 352-373. DOI: $10.35808 / \mathrm{ijeba} / 522$. 
Norena-Chavez, D. 2020. The Mediation Effect of Innovative Behavior on the Relationship Between Entrepreneurial Self-Efficacy and Entrepreneurial Intention.

International Journal of Economics and Business Administration, 8(4), 238-252. DOI: $10.35808 / \mathrm{ijeba} / 583$.

Obaid, S. 2017. The Impact of Knowledge Management Dimensions on Acquiring Competitive Advantage. An-Najah University Journal for Research (Humanities), 31(10), 1745-1782.

Olszak, C.M., Kisielnicki, J. 2016. Organizational creativity, and IT-based support: Informing Science. The International Journal of an Emerging Transdiscipline, 19, 103-123.

Park, J., Soo-Young, S., Sangmin, L. 2015. Human Resource Management Practices and Organizational Creativity: The Role of Chief Executive Officer's Learning Goal Orientation. Social Behavior and Personality, 43(6), 899-908. http://dx.doi.org/10.2224/sbp.2015.43.6.899.

Ramalingam, T., Abdul Karim, J., Piaralal, S., Singh, B. 2015. Creativity and Innovation (Organizational Factor) Influence on Firm Performance: An Empirical Study on Malaysian Telecommunication Mobile Network Operators. American Journal of Economics, 5(2), 194-199. DOI: 10.5923/c.economics.201501.24.

Rapeeporn, R., Klaus, E. 2020. Trust and knowledge sharing in context: A study of international buyer-supplier relationships in Thailand. Industrial Marketing Management, 88, 112-124.

Rasoul, G.K., Mohammad, H. 2016. A Model for Measuring the Direct and Indirect Impact of Business Intelligence on Organizational Agility with Partial Mediatory role of Empowerment (Case Study: Tehran Construction Engineering Organization (TCEO) and ETKA Organization Industries). Procedia-Social and Behavioral Sciences, 230, 413-421.

Sekaran, U., Bougie, R. 2016. Research Methods for Business: A Skill Building Approach,

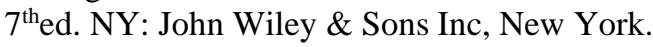

Silvio, L., Ivan, L., Ronaldo, C. 2018. Organizational creativity as a crucial resource for building international business competence, Vasconcellos, S.L.d. International Business Review. https://doi.org/10.1016/j.ibusrev.

Stachowiak, A., Szalapka, J. 2018. Agility Capability Maturity Framework. Procedia Manufacturing, 17, 603-610.

Zaisheng, Z., Fang, S., Zongbin, S. 2020. Promoting knowledge sharing in the workplace: Punishment v. reward. Chaos, Solitons \& Fractals, 131, 109518. 